\title{
openheart Clinical value of the $20 \%$ logistic EuroSCORE cut-off for selecting TAVI candidates: a single-centre cohort study analysis
}

\author{
Guram Imnadze, ${ }^{1}$ Steffen Hofmann, ${ }^{2}$ Michael Billion, ${ }^{2}$ Abbas Ferdosi, ${ }^{2}$ \\ Marek Kowalski, ${ }^{3}$ Ehab Rajab, ${ }^{2}$ Karin Bramlage, ${ }^{4}$ Peter Bramlage (D) , \\ Henning Warnecke, ${ }^{2,5}$ Norbert Franz ${ }^{3,5}$
}

\begin{abstract}
- Additional material is published online only. To view, please visit the journal online (http://dx.doi.org/10.1136/ openhrt-2019-001194).
\end{abstract}

To cite: Imnadze G, Hofmann S, Billion $\mathrm{M}$, et al. Clinical value of the $20 \%$ logistic EuroSCORE cut-off for selecting TAVI candidates: a single-centre cohort study analysis. Open Heart 2020;7:e001194. doi:10.1136/ openhrt-2019-001194

Received 23 0ctober 2019 Revised 22 January 2020 Accepted 3 February 2020

Check for updates

C) Author(s) (or their employer(s)) 2020. Re-use permitted under CC BY-NC. No commercial re-use. See rights and permissions. Published by BMJ.

\section{${ }^{1}$ Institut für}

Gesundheitsforschung und Bildung, Universität Osnabrück, Osnabrück, Germany ${ }^{2}$ Department of Cardiac Surgery, Schüchtermann Clinic, Bad Rothenfelde, Germany ${ }^{3}$ Department of Cardiology, Schüchtermann Clinic, Bad Rothenfelde, Germany ${ }^{4}$ Institute for Pharmacology and Preventive Medicine, Cloppenburg, Germany ${ }^{5}$ University Witten/ Herdecke, Witten, Germany

Correspondence to Prof Dr Peter Bramlage; peter. bramlage@ippmed.de

\section{ABSTRACT}

Background A logistic European System for Cardiac Operative Risk Evaluation (logEuroSCORE) $\geq 20 \%$ is frequently recognised as a finite criteria for transcatheter aortic valve implantation (TAVI) reimbursement, despite guideline modifications to reflect the appropriacy of TAVI in selected lower-risk patients. The aim was to evaluate the clinical value of this threshold cut-off in TAVI patients and to identify factors associated with mortality in those below this threshold.

Methods We analysed data from a single-centre, German, observational, TAVI-patient registry, gathered between 2008 and 2016. Patients were stratified by logEuroSCORE $(\geq$ or $<20 \%$ ) for comparisons. Logistic regression was performed to identify predictors of mortality at 1 year, with this analysis used to generate a calculated ('real') risk value for each patient.

Results 1679 patients (logEuroSCORE <20\%: $n=789$; logEurOSCORE $\geq 20 \%$ : $n=890$ ) were included. LogEuroSCORE $<20 \%$ patients were significantly younger (80.1 vs 81.6 years; $p<0.001$ ) and less comorbid than logEuroSCORE $\geq 20 \%$ patients, with a higher rate of transfemoral TAVI $(35.6 \%$ vs $26.1 \% ; p<0.001)$ and predilation $(70.0 \%$ vs $63.3 \%$; $p=0.004)$. Patients with a logEuroSCORE $<20 \%$ experienced more vascular complications (3.4\% vs $1.5 \%$; $p=0.010)$. One-year survival was $88.3 \%$ in the logEuroSCORE $<20 \%$ and $81.8 \%$ in the $\log$ EuroSCORE $\geq 20 \%$ group $(\mathrm{p}=0.005)$, with the calculated mortality risk falling within $2 \%$ of the logEuroSCORE in just $12.9 \%$ of patients. In the logEuroSCORE $<20 \%$ group, only coronary artery disease was significantly predictive of 1-year mortality (OR 2.408; 95\% Cl 1.361 to 4.262 ; $\mathrm{p}=0.003$ ).

Conclusions At our institution, patients with a logEuroSCORE $<20 \%$ selected for TAVI have excellent outcomes. The decision not to reimburse TAVI in such patients may be viewed as inappropriate.

\section{INTRODUCTION}

The European System for Cardiac Operative Risk Evaluation (EuroSCORE) was first introduced in 1999 as a tool for predicting the likelihood of operative mortality in cardiac

\section{Key questions}

What is already known about this subject?

- A logistic European System for Cardiac Operative Risk Evaluation (logEuroSCORE) $\geq 20 \%$ is frequently recognised as a finite criteria for transcatheter aortic valve implantation (TAVI) reimbursement, despite guideline modifications to reflect the appropriacy of TAVI in selected lower-risk patients.

What does this study add?

- Aim was to evaluate the clinical value of this threshold cut-off in TAVI patients in Germany and to identify factors associated with mortality in those below this threshold.

- At our institution, the outcomes of patients with a logEuroSCORE $<20 \%$ selected for TAVI by our multidisciplinary Heart Team were excellent, with good periprocedural safety and high rates of mediumterm survival.

How might this impact on clinical practice?

- Given the overwhelming evidence that the logEuroSCORE is inaccurate for identifying TAVI-associated mortality risk, we suggest that such non-specific scores should be given less importance when evaluating an individual's suitability for TAVI, with additional risk factors and the expert opinion of the Heart Team given greater weight.

- From a clinical perspective, coronary artery disease may deserve particular attention in patients with a logEuroSCORE $<20 \%$ being considered for TAVI.

surgical patients. ${ }^{1}$ The score takes into account a total of 17 objective risk factors encompassing patient-related, cardiac and operation-related variables. In Germany, it is one of the most widely used tools for preprocedural assessment of patients with severe symptomatic aortic stenosis (AS) being considered for aortic valve replacement (AVR).

The advanced age and multimorbidity of the AS population means that surgical AVR (SAVR) is typically a high-risk procedure. ${ }^{2}$ In 
recent years, transcatheter AVR (TAVI) has been widely adopted as a lower -risk, minimally invasive alternative. In their initial 2008 statement, European authorities proposed an arbitrary 20\% logistic EuroSCORE (logEuroSCORE) cut-off as a rough guide for identifying highrisk patients that may be more suited to TAVI than SAVR. ${ }^{3}$ However, in the same consensus document, the authors emphasised the score's modest accuracy and promoted its use in conjunction with informed clinical judgement. Current 2017 European guidelines now recommend that TAVI be considered in all patients with a logEuroSCORE $\geq 10 \%$, as well as in those with a score below this threshold but with additional significant risk factors. ${ }^{4}$ As such, conventional risk-stratification tools should be supplemented by a Heart Team's professional opinion when identifying good TAVI candidates. Despite these evidence-based guideline revisions, a logEuroSCORE of $20 \%$ continues to be recognised as the lower limit for TAVI candidates. ${ }^{5}$

The present real-world analysis aimed to evaluate the clinical value of the 20\% logEuroSCORE cut-off for identifying good TAVI candidates at our site. Factors associated with post-TAVI mortality in patients with a $\operatorname{logEuroSCORE}<20 \%$ were also explored, so as to aid clinical decision-making.

\section{METHODS}

The present study is a post hoc analysis of data from a single-centre, German, observational registry that was originally established as part of a quality assurance initiative. The registry's methodology has been previously described. ${ }^{67}$ Briefly, patients with severe AS undergoing TAVI between 2008 and 2016 were consecutively enrolled after providing their written informed consent to participate.

\section{Patients}

All patients with a diagnosis of severe, symptomatic AS that were scheduled to undergo TAVI at the Bad Rothenfelde Heart Centre were included. For the present analysis, patients without stated values for logEuroSCORE were excluded. No further inclusion/exclusion criteria applied.

The decision to perform TAVI was taken by the resident Heart Team, independently from the registry. In line with European guidelines, this decision was based on the patient being judged to be at high risk for SAVR following a comprehensive assessment that took into account the logEuroSCORE and other important risk factors, such as frailty, porcelain aorta and sequelae of chest radiation. ${ }^{4}$ The choice of access route was governed by the 'best for transfemoral (TF)' principle, which has been previously described. ${ }^{7}$ Briefly, unless a patient had all of the attributes comprising an ideal candidate for TF-TAVI, transapical (TA)-TAVI was preferentially performed.
For the present analysis, patients were divided into those with a logEuroSCORE of $<20 \%$ and those with a $\log$ EuroSCORE of $\geq 20 \%$.

\section{Procedures and documentation}

Baseline patient demographics, cardiac history, comorbidities and echocardiographic parameters were recorded prior to TAVI. Coronary artery disease (CAD) in our dataset is a clinical diagnosis which was not revalidated in the context of this registry. A logEuroSCORE value, the components of which are outlined in online supplementary table 1 , was calculated for each patient, as previously described. ${ }^{1}$

A trans-oesophageal echocardiography, coronary angiography and a CT scan were performed to aid access route and transcatheter heart valve size selection. All TAVI procedures were performed under general anaesthesia, according to standard site protocol. Periprocedural details and complications were documented and patients were followed up over the subsequent year. This period included outpatient visits or telephone interviews at 30 days, 6 and 12 months, during which data on vital status, complications and cardiovascular health were documented.

\section{Statistics}

Baseline and peri-procedural data were analysed using descriptive statistics, with continuous variables presented as means with $\mathrm{SD}$ and categorical variables presented as absolute numbers with percentages (\%). Comparisons between patients with a logEuroSCORE $<20 \%$ and those with a logEuroSCORE $\geq 20 \%$ were carried out using a Student's t-test or Mann-Whitney U test for continuous variables and a $\chi^{2}$ or Fisher's exact test for categorical variables . One-year Kaplan-Meier survival estimates were generated for each group and presented with a $p$ value calculated by Breslow test. Multivariate logistic regression including all documented baseline variables as covariables was carried out to identify predictors of mortality within the year following TAVI in the total study population, as well as in the logEuroSCORE $<20 \%$ group separately. These data are presented as ORs with $95 \%$ CIs and $p$ values.

To retrospectively determine each patient's 'calculated risk' of all-cause mortality at 1 year, output data from the regression analysis for the total population were entered into SPSS, alongside individual baseline patient data. This analysis generated a value for the 'real' probability of death at 1 year for each patient, expressed as a percentage (\%). Appendix 1 No calculated risk was generated for patients missing data for any of the baseline variables. Each patient's calculated risk was compared with their $\log$ EuroSCORE-predicted risk, with values within $\pm 2 \%$ considered comparable.

All statistical analysis was carried out using IBM SPSS, V.24.0 (IBM, Armonk, New York, USA), with a p value of $<0.05$ considered to be statistically significant. 


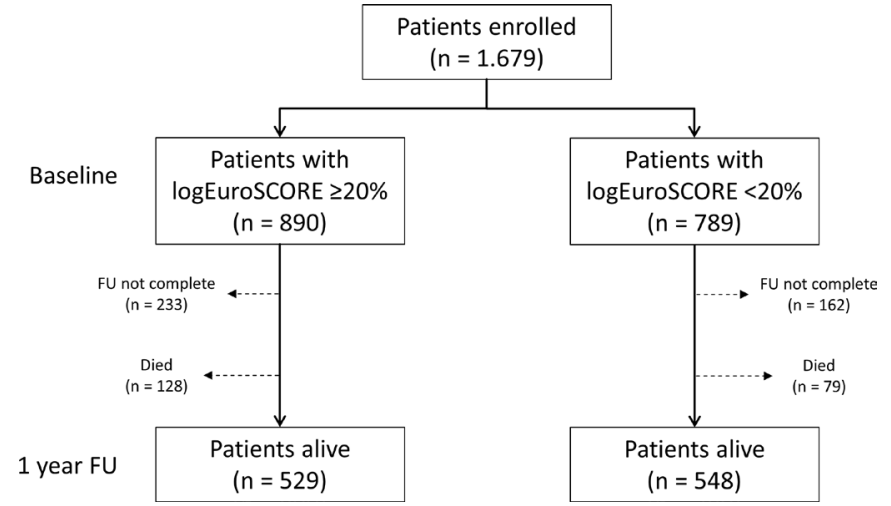

Figure 1 Patient flow. 'FU not complete' comprises all patients with a follow-up of $<1$ year or patients lost to followup. FU, follow-up; logEuroSCORE, logistic European System for Cardiac Operative Risk Evaluation.

\section{RESULTS}

A total of 1679 patients met the study inclusion criteria and underwent TAVI at our centre (figure 1). The baseline logEuroSCORE was $<20 \%$ in 789 patients $(47.0 \%)$ and $\geq 20 \%$ in 890 patients $(53.0 \%)$.

\section{Baseline patient characteristics}

Compared with patients with a logEuroSCORE $\geq 20 \%$, patients with a $\operatorname{logEuroSCORE}<20 \%$ were younger $(80.1 \% \pm 6.3 \%$ vs $81.6 \% \pm 5.4 \%$; $\mathrm{p}<0.001)$, had experienced fewer prior cardiac events/surgeries and were generally less comorbid (table 1 ). In addition, a significantly lower proportion were in New York Heart Association (NYHA) class III/IV (78.1\% vs $84.2 \%$; $<<0.001)$. The mean left ventricular ejection fraction (LVEF) was higher in the logEuroSCORE $<20 \%$ group $(57.4 \% \pm 10.3 \%$ vs $49.9 \% \pm 13.9 \% ; \mathrm{p}<0.001)$, as were the peak $(79.2 \pm 23.5$ vs $73.5 \pm 26.1 \mathrm{~mm} \mathrm{Hg} ; \mathrm{p}<0.001)$ and mean $(49.5 \pm 15.7$ vs $45.3 \pm 17.1 ; \mathrm{p}<0.001)$ transvalvular gradients.

\section{Peri-procedural details}

Although TA was the most common access route in both groups $(62.6 \%$ and $72.1 \%$, respectively), a higher

Table 1 Baseline patient characteristics

\begin{tabular}{|c|c|c|c|}
\hline & $\begin{array}{l}\text { logEuroSCORE } \geq 20 \% \text { mean } \pm \text { SD or } \\
n / N(\%) \\
(n=890)\end{array}$ & $\begin{array}{l}\text { logEuroSCORE }<20 \% \text { mean } \pm \text { SD or } \\
\mathrm{n} / \mathrm{N}(\%) \\
(\mathrm{n}=789)\end{array}$ & $P$ value \\
\hline Age (years) & $81.6 \pm 5.4$ & $80.1 \pm 6.3$ & $<0.001$ \\
\hline Female gender & 458/890 (51.5) & 444/789 (56.3) & 0.048 \\
\hline \multicolumn{4}{|l|}{ Cardiac history } \\
\hline Prior Ml & 207/884 (23.4) & 82/772 (10.6) & $<0.001$ \\
\hline Prior cardiac surgery* & $315 / 890(35.4)$ & $107 / 788(13.6)$ & $<0.001$ \\
\hline Prior stroke & 210/890 (23.6) & $54 / 788(6.9)$ & $<0.001$ \\
\hline \multicolumn{4}{|l|}{ Comorbidities } \\
\hline $\mathrm{AF}$ & $414 / 890(46.5)$ & $267 / 789(33.8)$ & $<0.001$ \\
\hline Hypertension & $844 / 890(94.8)$ & 738/789 (93.5) & 0.256 \\
\hline CAD & $593 / 883(67.2)$ & 374/772 (48.4) & $<0.001$ \\
\hline Mitral valve insufficiency $\left(>\|^{\circ}\right)$ & $54 / 888(6.1)$ & 19/785 (2.4) & $<0.001$ \\
\hline Porcelain aorta & 266/884 (30.1) & 212/773 (27.4) & 0.232 \\
\hline Pulmonary hypertension & $362 / 889(40.7)$ & $158 / 788(20.1)$ & $<0.001$ \\
\hline COPD & $204 / 890(22.9)$ & 140/789 (17.7) & 0.009 \\
\hline Diabetes mellitus & $304 / 890(34.2)$ & $214 / 789(27.1)$ & 0.002 \\
\hline Kidney insufficiency & $581 / 888(65.4)$ & $379 / 789(48.0)$ & $<0.001$ \\
\hline Dialysis & $36 / 888(4.1)$ & $10 / 789(1.3)$ & $<0.001$ \\
\hline NYHA class III or IV & 726/861 (84.3) & $579 / 741(78.1)$ & 0.001 \\
\hline LVEF (\%) & $49.9 \pm 13.9$ & $57.4 \pm 10.3$ & $<0.001$ \\
\hline Peak AV gradient (mm Hg) & $73.5 \pm 26.1$ & $79.2 \pm 23.5$ & $<0.001$ \\
\hline Mean AV gradient (mm Hg) & $45.3 \pm 17.1$ & $49.5 \pm 15.7$ & $<0.001$ \\
\hline STS score (\%) & $11.8 \pm 10.1$ & $8.0 \pm 8.3$ & $<0.001$ \\
\hline LogEuroSCORE (\%) & $34.5 \pm 13.0$ & $12.6 \pm 4.3$ & $<0.001$ \\
\hline
\end{tabular}

*Not including percutaneous coronary intervention.

AF, atrial fibrillation; AV, aortic valve; CAD, coronary artery disease; COPD, chronic obstructive pulmonary disease; logEuroSCORE, logistic European System for Cardiac Operative Risk Evaluation; LVEF, left ventricular ejection fraction; MI, myocardial infarction; NYHA, New York Heart Association; STS, Society of Thoracic Surgeons. 
Table 2 Peri-procedural details

\begin{tabular}{|c|c|c|c|}
\hline & $\begin{array}{l}\text { logEuroSCORE } \geq 20 \% \\
\mathrm{n} / \mathrm{N}(\%) \\
(\mathrm{n}=890)\end{array}$ & $\begin{array}{l}\text { logEuroSCORE <20\% } \\
\text { n/N (\%) } \\
(n=789)\end{array}$ & $P$ value \\
\hline Access route & & & $<0.001$ \\
\hline TF & $232 / 890(26.1)$ & $281 / 789(35.6)$ & \\
\hline TA & $642 / 890(72.1)$ & 494/789 (62.6) & \\
\hline Other & $16 / 890(1.8)$ & $14 / 789(1.8)$ & \\
\hline Valve type & & & 0.007 \\
\hline SAPIEN/SAPIEN XT & 735/890 (82.6) & 646/789 (81.9) & \\
\hline ACURATE & $142 / 890(16.0)$ & $142 / 789(18.0)$ & \\
\hline Others & $13 / 890(1.5)$ & $1 / 789(0.1)$ & \\
\hline BAV predilation & $563 / 890(63.3)$ & $552 / 789(70.0)$ & 0.004 \\
\hline \multicolumn{4}{|l|}{ Complications } \\
\hline Conversion to surgery & $4 / 890(0.4)$ & $6 / 789(0.8)$ & 0.530 \\
\hline Major vascular complications & $13 / 871(1.5)$ & 27/785 (3.4) & 0.010 \\
\hline PPI & $66 / 869(7.6)$ & 69/782 (8.8) & 0.363 \\
\hline New arrhythmia & $244 / 871(28.0)$ & 233/784 (29.7) & 0.444 \\
\hline Moderate-to-severe PVL & 9/857 (1.1) & $9 / 750(1.2)$ & 0.776 \\
\hline AKI requiring dialysis & $7 / 858(0.8)$ & 3/771 (0.4) & 0.349 \\
\hline Postdilation & $146 / 889(16.4)$ & 149/788 (18.9) & 0.182 \\
\hline In-hospital mortality & $26 / 880(3.0)$ & $21 / 788(2.7)$ & 0.721 \\
\hline
\end{tabular}

AKI, acute kidney injury; BAV, balloon aortic valvuloplasty; logEuroSCORE, logistic European System for Cardiac Operative Risk Evaluation; PPI, permanent pacemaker implantation; PVL, paravalvular leak; TA, transapical; TF, transfemoral.

proportion of the logEuroSCORE $<20 \%$ group underwent TAVI via the TF route compared with the logEuroSCORE $\geq 20 \%$ group $(35.6 \%$ vs $26.1 \%$; $\mathrm{p}<0.001)$ (table 2 ). The vast majority of patients received a SAPIEN/SAPIEN XT valve $(82.3 \%$ overall). Balloon aortic valvuloplasty (BAV) predilation was more frequently performed in the logEuroSCORE $<20 \%$ group than the logEuroSCORE $\geq 20 \%$ group $(70.0 \%$ vs $63.3 \%$; $\mathrm{p}=0.004)$.

The rates of conversion to surgery, permanent pacemaker implantation (PPI), new arrhythmia, moderate/ severe paravalvular regurgitation (PVL), acute kidney

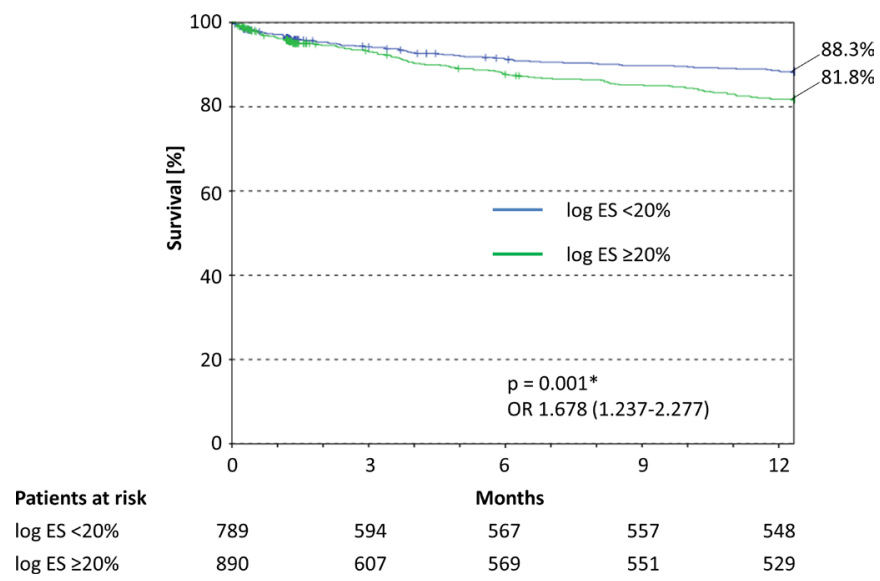

Figure 2 Kaplan-Meier survival curves for the year after TAVI. logES, logEuroSCORE. injury (AKI) requiring dialysis and balloon post-dilation were low and statistically comparable between groups (table 2). Though rare overall, major vascular complications were significantly more common in patients with a logEuroSCORE of $<20 \%$ than in those with a logEuroSCORE of $\geq 20 \%$ ( $3.4 \%$ vs $1.5 \%$; $p=0.010)$.

\section{Survival}

No statistical significant difference was found for in-hospital mortality between the two groups $(3.0 \%$ ( $\operatorname{logEuroSCORE} \geq 20 \%)$ vs $2.7 \%$ (logEuroSCORE $<20 \%)$; $\mathrm{p}=0.721$ ) (table 2). At 1 year post-TAVI, the estimated survival rate was significantly higher for patients with a $\operatorname{logEuroSCORE}<20 \%$ than for those with a logEuroSCORE $\geq 20 \%$ (88.3\% vs $81.8 \%$; $\mathrm{p}=0.005$ ) (figure 2). At 5 years post-TAVI, the estimated survival rate stayed significantly higher for patients with a logEuroSCORE $<20 \%(57.1 \%$ vs $44.3 \%$; $\mathrm{p}=0.005$ ) (online supplementary figure 1 ).

\section{Predictors of mortality at 1 year}

In the overall population, atrial fibrillation (AF; OR 1.758 ; $95 \%$ CI 1.267 to 2.439; $\mathrm{p}=0.001$ ), CAD (OR 1.559; $95 \%$ CI 1.054 to $2.306 ; \mathrm{p}=0.026$ ), kidney insufficiency (OR $1.458 ; 95 \%$ CI 1.021 to $2.084 ; \mathrm{p}=0.038$ ) and NYHA class III/IV (OR 1.824; 95\% CI 1.099 to 3.027; $\mathrm{p}=0.020$ ) were independent predictors of mortality at 1 year (table 3 ). A higher LVEF was protective, although the effect size was small (OR 0.985; 95\% CI 0.972 to $0.998 ; \mathrm{p}=0.020$ ). 
Table 3 Predictors of mortality at 1 year post-TAVI in the overall study population

\begin{tabular}{|c|c|c|c|c|}
\hline & $\begin{array}{l}\text { Univariate } \\
\text { OR (95\% Cl) }\end{array}$ & $P$ value & $\begin{array}{l}\text { Multivariate } \\
\text { OR }(95 \% \mathrm{Cl})^{*}\end{array}$ & $P$ value \\
\hline Age (years) & 0.997 (0.973 to 1.021$)$ & 0.779 & $1.002(0.972$ to 1.033$)$ & 0.903 \\
\hline Female gender & 0.796 (0.591 to 1.072 ) & 0.134 & 1.156 (0.811 to 1.646$)$ & 0.422 \\
\hline \multicolumn{5}{|l|}{ Cardiac history } \\
\hline Prior Ml & 1.333 (0.923 to 1.924) & 0.125 & 0.979 (0.638 to 1.502$)$ & 0.922 \\
\hline Prior cardiac surgery† & $1.220(0.882$ to 1.687$)$ & 0.229 & 0.881 (0.588 to 1.320$)$ & 0.540 \\
\hline Prior stroke & 1.062 (0.707 to 1.597) & 0.771 & 0.875 (0.561 to 1.364$)$ & 0.556 \\
\hline \multicolumn{5}{|l|}{ Comorbidities } \\
\hline $\mathrm{AF}$ & 2.140 (1.584 to 2.892) & $<0.001$ & 1.758 (1.267 to 2.439$)$ & 0.001 \\
\hline Hypertension & 1.390 (0.705 to 2.743$)$ & 0.342 & 0.879 (0.427 to 1.808$)$ & 0.725 \\
\hline CAD & 1.638 (1.188 to 2.258$)$ & 0.003 & 1.559 (1.054 to 2.306$)$ & 0.026 \\
\hline Mitral valve insufficiency $\left(>\|^{\circ}\right)$ & 1.225 (0.624 to 2.404) & 0.555 & $0.929(0.453$ to 1.905$)$ & 0.841 \\
\hline Porcelain aorta & 1.194 (0.864 to 1.649) & 0.283 & 1.117 (0.786 to 1.588$)$ & 0.537 \\
\hline Pulmonary hypertension & 1.475 (1.074 to 2.027) & 0.016 & 1.353 (0.958 to 1.909$)$ & 0.086 \\
\hline COPD & $1.383(0.980$ to 1.950$)$ & 0.065 & $1.156(0.792$ to 1.687$)$ & 0.451 \\
\hline Diabetes mellitus & 1.861 (1.354 to 2.559) & $<0.001$ & $1.238(0.876$ to 1.750$)$ & 0.226 \\
\hline Kidney insufficiency & $1.156(0.721$ to 1.854$)$ & 0.546 & 1.458 (1.021 to 2.084$)$ & 0.038 \\
\hline NYHA class III or IV & 2.233 (1.372 to 3.634$)$ & 0.001 & 1.824 (1.099 to 3.027$)$ & 0.020 \\
\hline LVEF (\%) & 0.976 (0.966 to 0.987$)$ & $<0.001$ & 0.985 (0.972 to 0.998$)$ & 0.020 \\
\hline Peak AV gradient (mm Hg) & 0.989 (0.983 to 0.995$)$ & 0.001 & $1.000(0.982$ to 1.017$)$ & 0.965 \\
\hline Mean AV gradient $(\mathrm{mm} \mathrm{Hg})$ & 0.983 (0.974 to 0.993$)$ & $<0.001$ & 0.994 (0.969 to 1.021) & 0.676 \\
\hline
\end{tabular}

${ }^{*}$ Adjusted for all other variables.

†Not including percutaneous coronary intervention.

AF, atrial fibrillation; COPD, chronic obstructive pulmonary disease; LVEF, left ventricular ejection fraction; MI, myocardial infarction; NYHA, New York Heart Association; STS, Society of Thoracic Surgeons; TA, transapical; TF, transfemoral.

Considering only patients with a logEuroSCORE of $<20 \%$, CAD was the only variable that remained a significant baseline predictor of 1-year mortality (OR 2.408; 95\% CI 1.361 to 4.262; $\mathrm{p}=0.003$ ) (table 4). AF also showed potential clinical, if not statistical, relevance (OR 1.620; 95\% CI 0.947 to $2.770 ; \mathrm{p}=0.078$ ).

\section{Calculated risk versus logEuroSCORE}

In total, 1132 patients had both a calculated risk value for mortality at 1 year and a baseline logEuroSCORE available. The calculated risk fell within $2 \%$ of the logEuroSCOREpredicted risk in just $12.9 \%$ of cases, being comparatively lower in $62.5 \%$ of patients (figure 3 ).

\section{DISCUSSION}

The present real-world analysis suggests that there is little clinical value in the 20\% logEuroSCORE cut-off. Indeed, despite obvious differences in baseline characteristics, patients both above and below the $20 \%$ threshold had excellent clinical outcomes, with low rates of peri-procedural complications and high survival rates at 1 year. Furthermore, the actual calculated risk of mortality following TAVI was below that predicted by the logEuroSCORE in over $60 \%$ of cases, demonstrating the score's inaccuracy in this indication. Among other variables, CAD was associated with a greater risk of mortality in the year after TAVI, remaining the only independent predictor in patients with a logEuroSCORE $<20 \%$. Raising awareness of this association among physicians may result in more appropriate treatment decisions.

\section{Peri-procedural outcomes}

Regardless of logEuroSCORE, the peri-procedural outcomes observed in the present study were highly satisfactory, with complications being extremely rare and largely comparable between the higher-risk and lowerrisk groups. This is in agreement with prior studies in lowrisk/intermediate-risk patients undergoing TAVI, which have also reported low rates of AKI, new arrhythmia and re-intervention. ${ }^{8-10}$ Importantly, such studies have found the risk of these events to be significantly reduced with TAVI compared with SAVR. ${ }^{8-11}$ This was recently reinforced by the publication of two major randomised trials, showing that the procedure is at least as safe or even superior in low-risk patients. ${ }^{12}{ }^{13}$ Furthermore, PPI was required by $<9 \%$ of patients in each of the present $\operatorname{logEuroSCORE}$ groups. This value is at the lower end of the rates reported by prior TAVI studies (range: $6.5 \%$ $33.7 \%^{14-18}$ ) and only slightly higher than those reported for low-risk/intermediate-risk patients undergoing 
Table 4 Predictors of mortality at 1 year post-TAVI in patients with a logEuroSCORE $<20 \%$

\begin{tabular}{|c|c|c|c|c|}
\hline & $\begin{array}{l}\text { Univariate } \\
\text { OR }(95 \% \mathrm{Cl})\end{array}$ & $P$ value & $\begin{array}{l}\text { Multivariate } \\
\text { OR }(95 \% \mathrm{Cl})^{*}\end{array}$ & $P$ value \\
\hline Age (years) & 1.001 (0.965 to 1.038$)$ & 0.947 & 0.996 (0.950 to 1.044$)$ & 0.868 \\
\hline Female gender & 1.176 (0.726 to 1.905$)$ & 0.509 & 1.482 (0.842 to 2.609$)$ & 0.172 \\
\hline \multicolumn{5}{|l|}{ Cardiac history } \\
\hline Prior Ml & 1.028 (0.488 to 2.165) & 0.942 & 0.854 (0.360 to 2.024$)$ & 0.720 \\
\hline Prior cardiac surgery† & 0.802 (0.397 to 1.620$)$ & 0.539 & 0.772 (0.337 to 1.771$)$ & 0.542 \\
\hline Prior stroke & 0.814 (0.312 to 2.123$)$ & 0.674 & 0.745 (0.248 to 2.236$)$ & 0.600 \\
\hline \multicolumn{5}{|l|}{ Comorbidities } \\
\hline AF & 1.716 (1.065 to 2.766$)$ & 0.027 & 1.620 (0.947 to 2.770) & 0.078 \\
\hline Hypertension & 1.991 (0.601 to 6.595) & 0.260 & 1.360 (0.389 to 4.761$)$ & 0.630 \\
\hline CAD & 1.815 (1.112 to 2.961$)$ & 0.017 & 2.408 (1.361 to 4.262 ) & 0.003 \\
\hline Mitral valve insufficiency $\left(>\|^{\circ}\right)$ & $1.757(0.485$ to 6.367$)$ & 0.391 & 1.636 (0.403 to 6.638$)$ & 0.491 \\
\hline Porcelain aorta & 1.263 (0.752 to 2.121) & 0.377 & 1.115 (0.638 to 1.950$)$ & 0.702 \\
\hline Pulmonary hypertension & 1.628 (0.905 to 2.928$)$ & 0.104 & 1.527 (0.797 to 2.926) & 0.202 \\
\hline COPD & 1.169 (0.648 to 2.110$)$ & 0.605 & 1.154 (0.605 to 2.202) & 0.664 \\
\hline Diabetes mellitus & 1.166 (0.692 to 1.964$)$ & 0.564 & 0.966 (0.539 to 1.733$)$ & 0.908 \\
\hline Kidney insufficiency & 1.156 (0.721 to 1.854$)$ & 0.546 & 0.983 (0.580 to 1.667$)$ & 0.949 \\
\hline NYHA class III or IV & 1.716 (0.853 to 3.453$)$ & 0.130 & 1.519 (0.732 to 3.152$)$ & 0.262 \\
\hline LVEF (\%) & 0.990 (0.969 to 1.011$)$ & 0.346 & 0.988 (0.964 to 1.013$)$ & 0.352 \\
\hline Peak AV gradient $(\mathrm{mm} \mathrm{Hg})$ & 1.002 (0.992 to 1.012$)$ & 0.747 & 0.999 (0.978 to 1.021$)$ & 0.931 \\
\hline Mean AV gradient $(\mathrm{mm} \mathrm{Hg})$ & 1.003 (0.988 to 1.018$)$ & 0.668 & 1.012 (0.981 to 1.045$)$ & 0.446 \\
\hline
\end{tabular}

${ }^{*}$ Adjusted for all other variables.

†Not including percutaneous coronary intervention.

$\mathrm{AF}$, atrial fibrillation; COPD, chronic obstructive pulmonary disease; LVEF, left ventricular ejection fraction; MI, myocardial infarction; NYHA, New York Heart Association; STS, Society of Thoracic Surgeons; TA, transapical; TF, transfemoral.

SAVR (range: $6.6 \%-7.3 \%^{8919}$ ). While vascular complications were more common in the logEuroSCORE $<20 \%$ compared with the logEuroSCORE $\geq 20 \%$ group, this is likely a result of TAVI being more commonly performed via the $\mathrm{TF}$ route in the former patients. Indeed, the greater risk of major vascular complications in TF-TAVI compared with TA-TAVI is well recognised. ${ }^{20}$ Nevertheless, the rate of $3.4 \%$ observed in the logEuroSCORE $<20 \%$ group is strikingly lower than the values reported by the majority of studies in low-risk/intermediate-risk patients undergoing TAVI or SAVR. ${ }^{819}$ This may be partly attributable to the 'best for TF' approach employed at our institution, given that only patients with the most compatible access vasculature undergo TF-TAVI. Overall, our data demonstrate that patients selected for TAVI by an expert Heart Team at our site have excellent periprocedural outcomes, regardless of whether or not they have a logEuroSCORE above or below the $20 \%$ cut-off. As such, this threshold appears to have little clinical value for discerning between good and poor candidates for TAVI.

\section{Mortality at 1 year}

The increased risk of mortality in elderly, multimorbid individuals undergoing open heart surgery is well recognised. Such characteristics feature heavily in surgical risk-stratification tools, ${ }^{21}$ the $\log$ EuroSCORE being no exception. ${ }^{1}$ Accordingly, it is appropriate for SAVR to be avoided in patients with a logEuroSCORE of $\geq 20 \%$ and for the minimally invasive alternative, TAVI, to be used. However, it does not necessarily follow that patients with a logEuroSCORE below this $20 \%$ threshold fail to benefit from TAVI. In the present study, 1-year survival rates were extremely high in the logEuroSCORE $<20 \%$ group, being similar to those previously reported for low-risk/ intermediate-risk patients undergoing SAVR. ${ }^{8}{ }^{19}$ While such comparisons are hindered by between-study heterogeneity, several important clinical trials have demonstrated a lower rate of all-cause mortality after TAVI compared with SAVR in patients at intermediate surgical risk. ${ }^{89}$ This trend was also reiterated by a recent, highprofile propensity score-matched analysis. ${ }^{19}$

Furthermore, our in-hospital mortality rates were low (logEuroSCORE $\geq 20 \%: 3.0 \%$ and $\log$ EuroSCORE $<20 \%$ : $2.7 \%$ ) compared with a large-scale, real-world German study. ${ }^{22}$ This study found TF-TAVI to result in similar or lower in-hospital mortality rates compared with SAVR across all surgical-risk groups (logEuroSCORE $<10 \%$ : $2.4 \%$ vs $2.0 \%, \mathrm{p}=0.302$; logEuroSCORE $10 \%-20 \%: 3.5 \%$ vs $5.3 \%, \mathrm{p}=0.025$; logEuroSCORE $20 \%-30 \%$ : $5.5 \%$ vs 


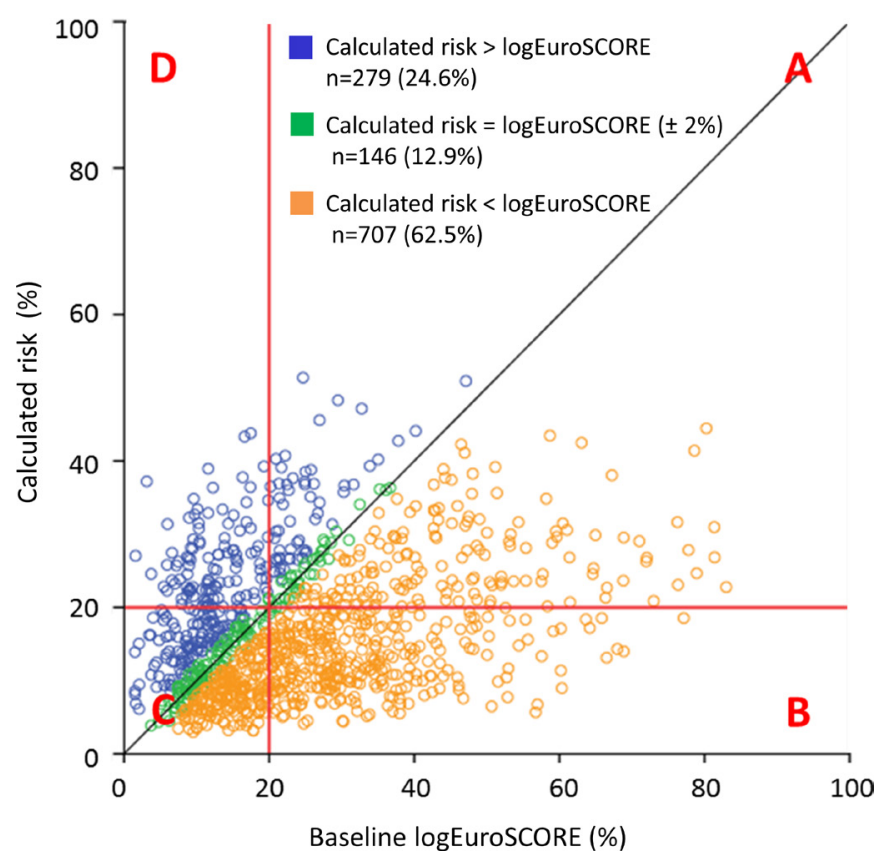

Figure 3 Calculated risk of mortality at 1 year compared with logEuroSCORE-predicted risk. $\mathrm{N}=1132$; calculated risk could not be generated for 547/1679 patients due to missing data for $\geq 1$ baseline variables. (A) Both logEuroSCORE and actual risk $\geq 20 \%$ ( $n=256$; 22.6\%); (B) logEuroSCORE $\geq 20 \%$ and calculated risk $<20 \%(\mathrm{n}=334 ; 29.5 \%)$; (C) both logEuroSCORE and calculated risk $<20 \%(n=432 ; 38.2 \%)$; (D) logEuroSCORE $<20 \%$ and calculated risk $\geq 20 \%$ ( $n=110$; 9.7\%). logEuroSCORE, logistic European System for Cardiac Operative Risk Evaluation.

$12.2 \%, \mathrm{p}<0.001$; $\log$ EuroSCORE $>30 \%: 6.5 \%$ vs $12.9 \%$, $\mathrm{p}=0.008) .{ }^{22}$ As such, it appears that informed selection of patients with a logEuroSCORE $<20 \%$ for TAVI can result in at least comparable survival compared with SAVR. As such, the use of a $20 \% \log$ EuroSCORE cut-off to denote automatic ineligibility for TAVI reimbursement may require revision.

\section{Predicting TAVI-related risk}

The fact that survival was greater in the logEuroSCORE $<20 \%$ group compared with the logEuroSCORE $\geq 20 \%$ group is unsurprising considering the differences in age and comorbidities at baseline. Indeed, all of the four variables identified as independent predictors of all-cause death within the overall population (AF, CAD, kidney insufficiency and NYHA class III/IV) were more prevalent in the logEuroSCORE $<20 \%$ group. However, of these, only renal insufficiency features in the logEuroSCORE algorithm. This may explain why the score was able to predict approximate trends in post-TAVI mortality but had limited accuracy for identifying actual risk, with $<13 \%$ of calculated risk values falling within $2 \%$ of the logEuroSCORE. As such, the present study adds to the considerable pool of evidence demonstrating the inappropriacy of the logEuroSCORE for predicting outcomes after TAVI. ${ }^{43-27}$ A number of TAVI-specific risk-assessment scores have been developed, including
SURTAVI, TARIS, FRANCE-2, TAVI2-SCORe, STT and OBSERVANT (contributory variables outlined in online supplementary table 2$)^{28-33}$; however, while several of these have shown promise, none has yet been extensively validated, adopted or endorsed by expert consensus. In Germany specifically, the re-calibrated German AV score (GAVS) II has been presented, although still offers only modest predictive ability (C-statistic: 0.74 ) and has only been validated in terms of in-hospital mortality. ${ }^{34}$ Consequently, the urgent need for a TAVI-specific, accurate risk-stratification system remains.

Besides being one of several variables associated with death in the overall study population, CAD was the only independent predictor of 1-year mortality in patients with a $\operatorname{logEuroSCORE}<20 \%$, increasing the risk more than twofold. This likely reflects the reduced capacity of patients with CAD to tolerate the ischaemic and haemodynamic burden of the procedure, which includes rapid ventricular pacing, balloon inflation and periods of hypotension. CAD does not specifically feature in the logEuroSCORE; however, it has been previously recognised as a key risk factor in TAVI patients and is included in both the SURTAVI and GAVS II TAVI-specific risk-assessment tools. ${ }^{334} \mathrm{CAD}$ and AS commonly coexist due to shared risk factors and mechanisms of pathogenesis. ${ }^{35}{ }^{36}$ Fortunately, the former condition may be treated through coronary artery bypass grafting or percutaneous coronary intervention (PCI) ${ }^{37} 38$ Several studies have shown that such revascularisation prior to treatment of the AS results in improved long-term outcomes ${ }^{39}$; however, these studies have mainly been performed in SAVR patients and few data exist in the context of TAVI. Nevertheless, ESC guidelines contain a class IIa recommendation for PCI to be considered in patients with a primary indication for TAVI and coronary artery diameter stenosis $>70 \%$ in proximal segments. ${ }^{4}$ Our data suggest that the resolution of CAD prior to TAVI may allow better outcomes, especially in patients with a $\log \mathrm{Eu}-$ roSCORE $<20 \%$, and this merits further investigation. The incorporation of CAD into future TAVI-specific risk scores should also be considered.

Interestingly, a clinically (if not statistically) significant association between AF and post-TAVI mortality risk was observed in patients with a logEuroSCORE of $<20 \%$. AF has been widely associated with poorer longterm survival and stroke in patients with AS, regardless of treatment approach or classically assessed procedural risk $^{40}$; however, this effect appears to be largely related to a lack of guidelines for optimum antithrombotic therapy regimens during AVR. Development of such standardised recommendations would likely reduce the risk of thromboembolic events and bleeding complications in patients with AF undergoing TAVI, translating into a lower mortality risk and enabling more low-risk patients to safely undergo the procedure.

\section{Limitations}

Given that the present study was based on TAVI-specific data from a quality assurance initiative, SAVR data were 
unavailable for comparison. This limits the conclusions we are able to draw regarding the choice between TAVI and SAVR in low-risk patients. Nevertheless, our data suggest the inappropriacy of using a finite logEuroSCORE $<20 \%$ cut-off to indicate that TAVI would not be beneficial. A second limitation is the proportional difference in TAVI access routes between low-risk and high-risk groups, which may have influenced outcomes. Nevertheless, route selection was based on comprehensive patient assessment by an expert Heart Team and is representative of real-world practice, with other registries also reporting a higher frequency of TF-TAVI in low-risk patients. ${ }^{41}$ Third, some patients in the present study underwent TAVI a considerable number of years ago, with the procedure's rapid evolution in recent years having resulted in contemporary improvements in valve technology and operator experience. ${ }^{41}$ Furthermore, BAV predilation, which at the beginning of the study was a mandatory step in the TAVI procedure and is thus highly prevalent in the present dataset, is now considered largely unnecessary in the majority of patients and may even be harmful. ${ }^{42}$ As such, our data may underestimate the up-to-date safety/ efficacy of the TAVI procedure. Finally, the study was confined to a single German site that adopts the 'best for TF' method for access route selection. As such, our findings may not be generalisable to centres in other countries or that employ alternative approaches to access decision.

\section{CONCLUSIONS}

At our institution, the outcomes of patients with a $\operatorname{logEuroSCORE}<20 \%$ selected for TAVI by our multidisciplinary Heart Team were excellent, with good periprocedural safety and high rates of medium-term survival. Given the overwhelming evidence that the logEuroSCORE is inaccurate for identifying TAVI-associated mortality risk, we suggest that such non-specific scores should be given less importance when evaluating an individual's suitability for TAVI, with additional risk factors and the expert opinion of the Heart Team given greater weight. From a clinical perspective, CAD may deserve particular attention in patients with a $\log$ EuroSCORE $<20 \%$ being considered for TAVI.

Contributors All authors except PB and KB established and conducted the registry. $\mathrm{PB}$ and $\mathrm{KB}$ designed the statistical approach, analysis and interpretation. $\mathrm{Gl}$ and $\mathrm{PB}$ outlined the first version of the manuscript, which all other authors revised for important intellectual content. KB performed the statistical analyses. All authors approved the final version of the manuscript to be submitted.

Funding The authors have not declared a specific grant for this research from any funding agency in the public, commercial or not-for-profit sectors.

Competing interests $\mathrm{PB}$ is a consultant for Edwards Lifesciences.

Patient consent for publication Not required.

Ethics approval The study was approved by the responsible ethics committee in Hannover (Landesärztekammer) and was carried out in accordance with the declaration of Helsinki and its amendments.

Provenance and peer review Not commissioned; externally peer reviewed.
Data availability statement Data are available on reasonable request from the corresponding author.

Open access This is an open access article distributed in accordance with the Creative Commons Attribution Non Commercial (CC BY-NC 4.0) license, which permits others to distribute, remix, adapt, build upon this work non-commercially, and license their derivative works on different terms, provided the original work is properly cited, appropriate credit is given, any changes made indicated, and the use is non-commercial. See: http://creativecommons.org/licenses/by-nc/4.0/.

ORCID iD

Peter Bramlage http://orcid.org/0000-0003-4970-2110

\section{REFERENCES}

1 Nashef SA, Roques F, Michel P, et al. European system for cardiac operative risk evaluation (EuroSCORE). Eur J Cardiothorac Surg 1999;16:9-13.

2 Osnabrugge RLJ, Mylotte D, Head SJ, et al. Aortic stenosis in the elderly: disease prevalence and number of candidates for transcatheter aortic valve replacement: a meta-analysis and modeling study. J Am Coll Cardiol 2013;62:1002-12.

3 Vahanian A, Alfieri O, Al-Attar N, et al. Transcatheter valve implantation for patients with aortic stenosis: a position statement from the European association of Cardio-Thoracic surgery (EACTS) and the European Society of cardiology (ESC), in collaboration with the European association of percutaneous cardiovascular interventions (EAPCI). Eur Heart J 2008;29:1463-70.

4 Baumgartner H, Falk V, Bax JJ, et al. 2017 ESC/EACTS guidelines for the management of valvular heart disease. Eur Heart $J$ 2017;38:2739-91.

5 Kölbel R. Abrechnungsverstöße in Der stationären medizinischen Versorgung: Medizinische, ökonomische und juristische Perspektiven. Kohlhammer Verlag, 2013.

6 Imnadze G, Hofmann S, Billion M, et al. Transapical transcatheter aortic valve implantation in patients with a low ejection fraction. Interact Cardiovasc Thorac Surg 2018;26:224-9.

7 Kowalski M, Deutsch C, Hofmann S, et al. Transcatheter aortic valve implantation at a high-volume center: the bad Rothenfelde experience. Kitp 2017;4:215-24.

8 Leon MB, Smith CR, Mack MJ, et al. Transcatheter or surgical aortic-valve replacement in intermediate-risk patients. N Engl J Med 2016;374:1609-20.

9 Reardon MJ, Van Mieghem NM, Popma JJ, et al. Surgical or transcatheter aortic-valve replacement in intermediate-risk patients. N Engl J Med 2017;376:1321-31.

10 Garg A, Rao SV, Visveswaran G, et al. Transcatheter aortic valve replacement versus surgical valve replacement in Low-Intermediate surgical risk patients: a systematic review and meta-analysis. $J$ Invasive Cardiol 2017;29:209-16.

11 Siemieniuk RA, Agoritsas T, Manja V, et al. Transcatheter versus surgical aortic valve replacement in patients with severe aortic stenosis at low and intermediate risk: systematic review and metaanalysis. BMJ 2016;354:i5130.

12 Mack MJ, Leon MB, Thourani VH, et al. Transcatheter aortic-valve replacement with a Balloon-Expandable valve in low-risk patients. $N$ Engl J Med 2019;380:1695-705.

13 Popma JJ, Deeb GM, Yakubov SJ, et al. Transcatheter aortic-valve replacement with a self-expanding valve in low-risk patients. $N$ Engl $J$ Med 2019;380:1706-15.

14 Ledwoch J, Franke J, Gerckens U, et al. Incidence and predictors of permanent pacemaker implantation following transcatheter aortic valve implantation: analysis from the German transcatheter aortic valve interventions registry. Catheter Cardiovasc Interv 2013;82:n/ a-77.

15 Erkapic D, De Rosa S, Kelava A, et al. Risk for permanent pacemaker after transcatheter aortic valve implantation: a comprehensive analysis of the literature. J Cardiovasc Electrophysiol 2012;23:391-7.

16 Hoyt MJ, Hathaway J, Palmer R, et al. Predictors of permanent pacemaker implantation after transcatheter aortic valve replacement. $J$ Cardiothorac Vasc Anesth 2015;29:1162-6.

17 Maan A, Refaat MM, Heist EK, et al. Incidence and predictors of pacemaker implantation in patients undergoing transcatheter aortic valve replacement. Pacing Clin Electrophysiol 2015;38:878-86.

18 Khatri PJ, Webb JG, Rodés-Cabau J, et al. Adverse effects associated with transcatheter aortic valve implantation: a metaanalysis of contemporary studies. Ann Intern Med 2013;158:35-46. 
19 Thourani VH, Kodali S, Makkar RR, et al. Transcatheter aortic valve replacement versus surgical valve replacement in intermediate-risk patients: a propensity score analysis. The Lancet 2016;387:2218-25

20 Schymik G, Würth A, Bramlage P, et al. Long-Term results of transapical versus transfemoral TAVI in a real world population of 1000 patients with severe symptomatic aortic stenosis. Circulation 2015;8.

21 Prins C, de Villiers Jonker I, Botes L, et al. Cardiac surgery risk stratification models. Cardiovasc J Afr 2012;23:160-4.

22 Möllmann H, Bestehorn K, Bestehorn M, et al. In-Hospital outcome of transcatheter vs. surgical aortic valve replacement in patients with aortic valve stenosis: complete dataset of patients treated in 2013 in Germany. Clin Res Cardiol 2016;105:553-9.

23 Sedaghat A, Sinning J-M, Vasa-Nicotera M, et al. The revised EuroSCORE II for the prediction of mortality in patients undergoing transcatheter aortic valve implantation. Clin Res Cardiol 2013;102:821-9.

24 Watanabe Y, Hayashida K, Lefèvre T, et al. Is euroscore II better than EuroSCORE in predicting mortality after transcatheter aortic valve implantation? Cathet Cardiovasc Intervent 2013;81:1053-60.

25 Hemmann K, Sirotina M, De Rosa S, et al. The STS score is the strongest predictor of long-term survival following transcatheter aortic valve implantation, whereas access route (transapical versus transfemoral) has no predictive value beyond the periprocedural phase. Interact Cardiovasc Thorac Surg 2013;17:359-64.

26 Sinning J-M, Wollert KC, Sedaghat A, et al. Risk scores and biomarkers for the prediction of 1-year outcome after transcatheter aortic valve replacement. Am Heart J 2015;170:821-9.

27 Silaschi M, Conradi L, Seiffert M, et al. Predicting risk in transcatheter aortic valve implantation: comparative analysis of EuroSCORE II and established risk stratification tools. Thorac Cardiovasc Surg 2015;63:472-8.

28 Seiffert M, Sinning J-M, Meyer A, et al. Development of a risk score for outcome after transcatheter aortic valve implantation. Clin Res Cardiol 2014;103:631-40.

29 lung B, Laouénan C, Himbert D, et al. Predictive factors of early mortality after transcatheter aortic valve implantation: individual risk assessment using a simple score. Heart 2014;100:1016-23.

30 Debonnaire P, Fusini L, Wolterbeek R, et al. Value of the "TAVI2SCORe" versus surgical risk scores for prediction of one year mortality in 511 patients who underwent transcatheter aortic valve implantation. Am J Cardiol 2015;115:234-42.
31 D'Ascenzo F, Capodanno D, Tarantini G, et al. Usefulness and validation of the survival posT TAVI score for survival after transcatheter aortic valve implantation for aortic stenosis. Am J Cardiol 2014;114:1867-74.

32 Capodanno D, Barbanti M, Tamburino C, et al. A simple risk tool (the OBSERVANT score) for prediction of 30-day mortality after transcatheter aortic valve replacement. Am J Cardiol 2014;113:1851-8.

33 van Mieghem NM, Head SJ, van der Boon RMA, et al. The SURTAVI model: proposal for a pragmatic risk stratification for patients with severe aortic stenosis. Eurolntervention 2012;8:258-66.

34 Schiller W, Barnewold L, Kazmaier T, et al. The German aortic valve score II. Eur J Cardiothorac Surg 2017;52:881-7.

35 Rapp AH, Hillis LD, Lange RA, et al. Prevalence of coronary artery disease in patients with aortic stenosis with and without angina pectoris. Am J Cardiol 2001;87:1216-7.

36 Stewart BF, Siscovick D, Lind BK, et al. Clinical factors associated with calcific aortic valve disease. cardiovascular health study. J Am Coll Cardiol 1997;29:630-4.

37 Virk SA, Tian DH, Liou K, et al. Systematic review of percutaneous coronary intervention and transcatheter aortic valve implantation for concomitant aortic stenosis and coronary artery disease. Int $J$ Cardiol 2015;187:453-5.

38 Dellis SL, Akujuo AC, Bennett EV, et al. Off-Pump coronary artery bypass grafting and Transaortic transcatheter aortic valve replacement. J Card Surg 2016;31:435-8.

39 Lund O, Nielsen TT, Pilegaard HK, et al. The influence of coronary artery disease and bypass grafting on early and late survival after valve replacement for aortic stenosis. J Thorac Cardiovasc Surg 1990;100:327-37.

40 Tarantini G, Mojoli M, Urena M, et al. Atrial fibrillation in patients undergoing transcatheter aortic valve implantation: epidemiology, timing, predictors, and outcome. Eur Heart J 2017;38:1285-93.

41 Barbash IM, Finkelstein A, Barsheshet A, et al. Outcomes of patients at estimated low, intermediate, and high risk undergoing transcatheter aortic valve implantation for aortic stenosis. Am J Cardiol 2015;116:1916-22.

42 Bagur R, Kwok CS, Nombela-Franco L, et al. Transcatheter aortic valve implantation with or without preimplantation balloon aortic valvuloplasty: a systematic review and Meta-Analysis. J Am Heart Assoc 2016;5. 